\title{
Disinfection effects of undoped and silver-doped ceria powders of nanometer crystallite size
}

\author{
This article was published in the following Dove Press journal: \\ International Journal of Nanomedicine \\ 2 June 2016 \\ Number of times this article has been viewed
}

\section{Dah-Shyang Tsai' \\ Tzu-Sen Yang ${ }^{2,3}$ \\ Yu-Sheng Huang' \\ Pei-Wen Peng ${ }^{2,4}$ \\ Keng-Liang $\mathrm{Ou}^{3,4}$}

'Department of Chemical Engineering, National Taiwan University of Science and Technology, ${ }^{2}$ School of Dental Technology, ${ }^{3} \mathrm{Graduate}$ Institute of Biomedical Materials and Tissue Engineering, ${ }^{4}$ Research Center for Biomedical Implants and Microsurgery Devices, Taipei Medical University, Taipei, Taiwan
Correspondence: Tzu-Sen Yang Graduate Institute of Biomedical Materials and Tissue Engineering, Taipei Medical University, 250 Wu-Hsing Street, Taipei City I I0, Taiwan

Tel +88622736 I66I 5206

Email tsyang@tmu.edu.tw

\begin{abstract}
Being endowed with an ability of capturing and releasing oxygen, the ceria surface conventionally assumes the role of catalyzing redox reactions in chemistry. This catalytic effect also makes possible its cytotoxicity toward microorganisms at room temperature. To study this cytotoxicity, we synthesized the doped and undoped ceria particles of 8-9 $\mathrm{nm}$ in size using an inexpensive precipitation method and evaluated their disinfecting aptitudes with the turbidimetric and plate count methods. Among the samples being analyzed, the silver-doped ceria exhibits the highest sterilization ability, yet the undoped ceria is the most intriguing. The disinfection effect of undoped ceria is moderate in magnitude, demanding a physical contact between the ceria surface and bacteria cell wall, or the redox catalysis that can damage the cell wall and result in the cell killing. Evidently, this effect is short-range and depends strongly on dispersion of the nanoparticles. In contrast, the disinfection effects of silver-doped ceria reach out several millimeters since it releases silver ions to poison the surrounding microorganisms. Additionally, the aliovalent silver substitution creates more ceria defects. The synergetic combination, silver poisoning and heterogeneous redox catalysis, lifts and extends the disinfecting capability of silver-doped ceria to a superior level.
\end{abstract}

Keywords: ceria nanoparticle, antibacterial activity, cytotoxicity, oxygen vacancy, reactive oxygen species

\section{Introduction}

The cerium oxide lattice is known for its high tolerance to reversible cycles of oxygenation/deoxygenation without structure collapse enabling it to serve as an oxygen buffer in catalysis chemistry. ${ }^{1,2}$ The buffer function is made easy since cerium coexists in two oxidation states, trivalent $\mathrm{Ce}^{3+}$ and the tetravalent $\mathrm{Ce}^{4+}$. Hence, cerium oxide acts as an oxygen provider under the oxygen-deficient environment; for instance, it is added in the diesel engine at ppm level to enhance the combustion efficiency. ${ }^{3-5}$ After the oxide surface gives away its oxygen, $\mathrm{Ce}^{4+}$ is reduced to $\mathrm{Ce}^{3+}$ due to an extra electron left behind. And the surface reduction gives rise to oxygen vacancy formation, accompanying with color change. Researchers suggest this color variation be developed into a portable ceria-based assay for detecting food antioxidants. ${ }^{6}$ When the oxide surface is sufficiently reduced and rich in $\mathrm{Ce}^{3+}$, it is inclined to receive oxygen again. The reduced oxide may perform as an antioxidant in biomedical applications. Seal and Self have demonstrated that high-surface-area cerium oxide nanoparticles (CeONP) possess superoxide radicals scavenging capability just like superoxide dismutase. ${ }^{7-9}$ Other reactive oxygen species (ROS), such as hydroxyl radical, ${ }^{10}$ nitric oxide, ${ }^{11}$ and hydrogen peroxide, ${ }^{12}$ may also be scavenged by CeONP at physiological $\mathrm{pH}$ values. These in vitro studies suggest CeONP is a potential therapeutic agent for diseases. And $\mathrm{pH}$ is a decisive factor in driving $\mathrm{CeONP}$ to be an oxidant or antioxidant. 
The reports on cancer cells have also indicated a minimum toxicity toward normal mammalian tissues, and an innate cytotoxicity to cancer cells. These positive results have been reviewed and the authors point out the application opportunities of CeONP on treating the cancers associated to ROS regulation problems, ${ }^{13,14}$ but the authors also warn the readers about the inconsistency among published data. ${ }^{15-17}$

Another urgent issue of the health care system is the evergrowing resistance that bacteria develop to many organic antibacterial agents because of their rapid evolution rates. CeONP provides a different mechanism on killing bacteria or restricting their cell growth. Research efforts on its toxicity could yield new approaches in disinfecting textiles, food packaging, and water. CeONP toxicity toward microorganisms is generally attributed to oxidative stress and membrane disruption. Both mechanisms require direct contact with cell wall and good dispersion of nanoparticles. ${ }^{18-20}$ Nonetheless, literature reports the toxicity details differ considerably, depending on the types of microorganism, the growth media, particle-size, and $\mathrm{pH}$ value. ${ }^{21-23}$ When biocompatible polymers, such as dextran and polyacrylic acid, are applied, more complications are involved. ${ }^{24-27}$

In this work, we prepare the doped and undoped ceria particles of nanometer size using a cost-effective method and investigate their effects on growth inhibition of both the Gram-positive and -negative bacterial cells. The results show that silver-doped CeONP not only releases silver ions but also increases oxygen vacancies on the oxide surface. Thus, silver dopant introduces the disinfection effect of $\mathrm{Ag}$, which has been reported effective against some drug-resistant bacteria by means of silver nanoparticles. ${ }^{28,29}$ Silver-doped CeONP further associates the two effects of ceria redox disinfection and the bacteria killing of silver synergistically and provides an alternative to upgrade the sterilization effects on bacteria and benefit the health care community.

\section{Materials and methods}

\section{Powder synthesis and characterization}

The samples of ceria nanoparticles were prepared using a facile precipitation method with caustic soda precipitant. Typically, the weighed powders of cerium nitrate were mixed with and without stoichiometric precursors of $10 \mathrm{~mol} \%$ silver, aluminum, copper, chromium nitrates, and dissolved to make $0.1 \mathrm{M}$ solutions of $1 \mathrm{~L}$ in volume. Precipitation occurred as $0.4 \mathrm{M}$ caustic soda was added dropwise into the nitrate solution. The hydroxide precipitates of pale purple color were filtered and washed with deionized water of sufficient amount to remove residual sodium and dried at $120^{\circ} \mathrm{C}$. The resulting undoped and aluminum-doped samples were yellow in color, while the silver-doped sample was black, and the chromiumand copper-doped samples appeared brown.

Phase analysis was performed with the X-ray diffractometer equipped with a copper $\mathrm{K} \alpha$ radiation source and nickel filter (Bruker D2 Phaser; Bruker AXS, Karlsruhe, Germany). The crystallite size was estimated using the Scherrer formula, $0.9 \lambda B \cos \theta$, in which $\lambda$ is the wavelength $(0.15406 \mathrm{~nm})$, and $B$ is the full width at half maximum of the diffraction line at Bragg angle $\theta$. Raman spectra were measured in the backscattering mode at room temperature, using a Renishaw inVia micro-Raman system equipped with a 1,800 grooves/ $\mathrm{mm}$ grating and an optical microscope. The radiation source was an Ar ion laser beam of wavelength $514.5 \mathrm{~nm}$, which was focused on a spot of $5 \mu \mathrm{m}$ in diameter at $150 \mathrm{~mW}$. Each recording was acquired after accumulation of 100 scans with an exposure time 10 seconds. The agglomerate size distribution of CeONP suspension was determined using the dynamic light scattering technique (Zetasizer, Nano ZS, Malvern Instruments, Malvern, UK). Silver concentrations of the broth, after filtering out the Ag-doped ceria sample, were measured using an inductively coupled plasma mass spectrometer (ICP-MS, JY 2000-2, HORIBA Ltd., Kyoto, Japan).

\section{Preparation of bacterial cells and assay for antimicrobial activity}

Gram-negative bacteria Escherichia coli (ATCC 25922) and Gram-positive bacteria Staphylococcus aureus (BCRC 10908), maintained as stock cultures at $-80^{\circ} \mathrm{C}$, were revived through growing on Luria-Bertani (LB) broth (Miller Code No 7279A) and tryptic soy broth plates (Acumedia 7164A) at $37^{\circ} \mathrm{C}$ for 16 hours, respectively. In this study, the $\mathrm{pH}$ of LB solution was adjusted to $7.3 \pm 0.2$.

To evaluate growth inhibition of the ceria-based powders, growth rate and bacterial concentrations were determined by the standard turbidimetric determination and plate count methods. The plate count method begins with weighing a proper amount of ceria-based powder ranging from 0 to $80 \mathrm{mg}$ in $125 \mathrm{~mL}$ flasks, followed by sterilization of nanoparticles in an autoclave prior to assay for the determination of antimicrobial activity. Then, $40 \mathrm{~mL}$ of bacterial cells suspension $\left(5 \times 10^{5}\right.$ colony-forming units $\left.[\mathrm{CFU}] / \mathrm{mL}\right)$ was added into the sterilized powder such that the final concentration fell in the range of $0-2 \mathrm{mg} / \mathrm{mL}$ in several flasks. All the flasks were subsequently incubated in the orbital shaking incubator at $200 \mathrm{rpm}$ at $37^{\circ} \mathrm{C}$ for 24 hours. The cytotoxicity was assessed by counting CFU on LB agar plates after $37^{\circ} \mathrm{C}$ incubation. The cytotoxicity was also assessed by measuring 
the optical density (OD) at wavelength $600 \mathrm{~nm}$, using a Genesys $^{\mathrm{TM}} 10$ UV-Visible spectrophotometer (Thermo Fisher Scientific, Waltham, MA, USA), where OD of 0.06 at $600 \mathrm{~nm}$ corresponds to a concentration of $10^{8} \mathrm{CFU} / \mathrm{mL}$. Experiments on growth kinetics were repeated three times and data were expressed as mean \pm standard deviation.

\section{Detection of ROS}

The ROS formed by silver-doped ceria nanoparticles was identified with $2^{\prime}, 7^{\prime}$-dichloro-fluorescein diacetate (DCFH-DA; Cell Biolabs, San Diego, CA, USA). Initially, $20 \mu \mathrm{L}$ of bacterial cells suspensions, either E. coli or $S$. aureus, at $2 \times 10^{6} \mathrm{CFU} / \mathrm{mL}$, were added into the $20 \mu \mathrm{L}$ of 40 $\mu \mathrm{M}$ DCFH-DA at $37^{\circ} \mathrm{C}$ for 1 hour, followed by mixing with the prescribed amounts of silver-doped ceria nanoparticles such that the final concentrations were 0.25 and $1.0 \mathrm{mg} /$ $\mathrm{mL}$, respectively, for real-time probing of the intracellular ROS generation in E. coli and S. aureus cells. Finally, the
ROS formed in the sample was detected using an inverted fluorescence microscope (TE2000U; Nikon, Tokyo, Japan), equipped with an objective lens (Plan Apo 60x/1.40 oil, Nikon), band-pass filters for DCFH-DA, and EMCCD camera (LucaEM DL6581; Andor, CT, USA).

\section{Results and discussion Doped and undoped ceria nanoparticle characterization}

Figure 1A presents X-ray diffraction results of the silver-doped and undoped CeONP, which display explicit features of cubic fluorite structure. Diffraction patterns of other cation-doped ceria are not shown since they resemble that of the undoped sample. The fitted lattice parameters of doped and undoped samples, based on ten line positions of each diffraction pattern, are listed in Table 1. The lattice parameter of undoped CeONP is $0.5412 \mathrm{~nm}$, consistent with the values reported in literature on ceria powder samples. ${ }^{30,31}$ Table 1 indicates
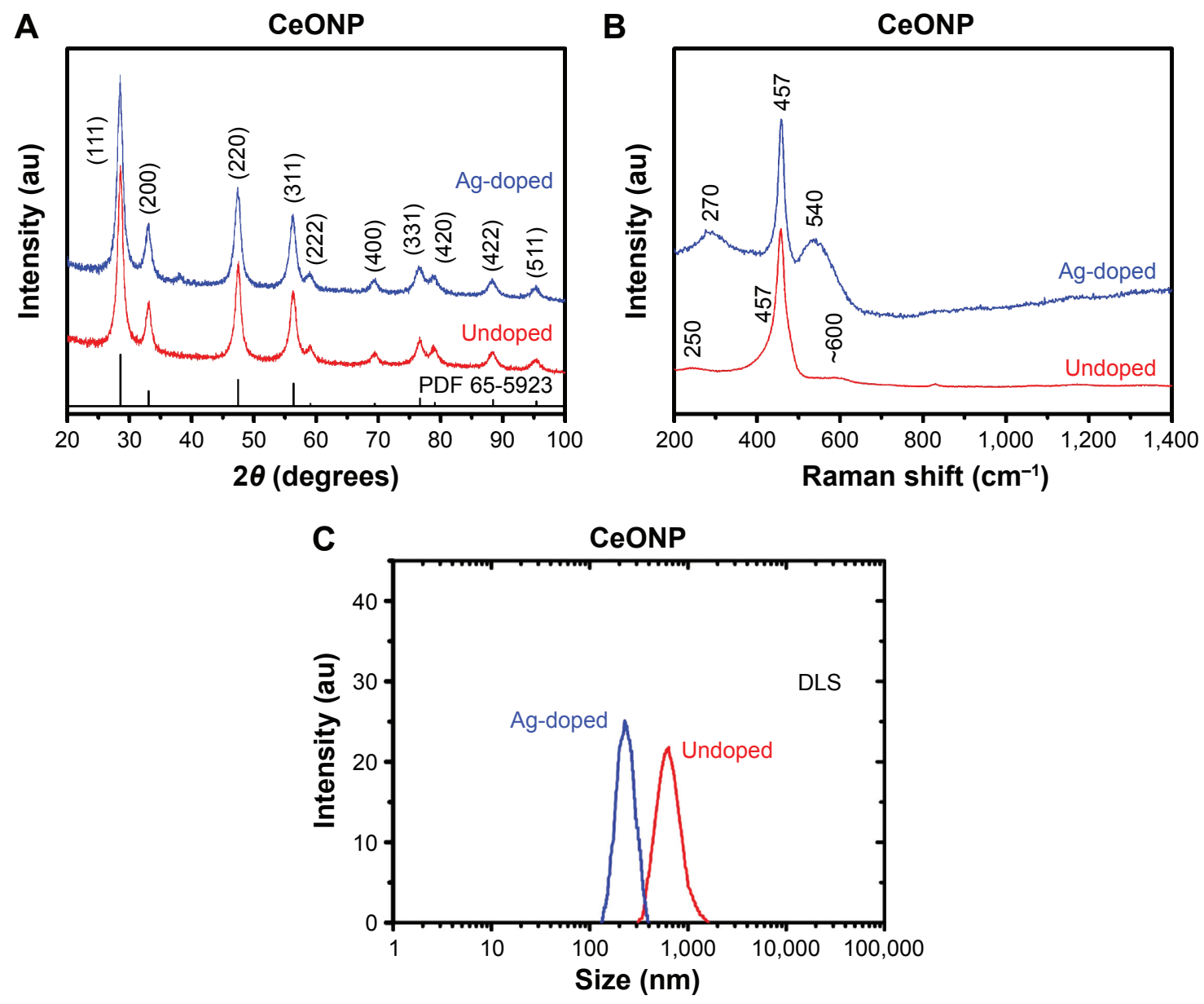

Figure I Diffraction, Raman, and DLS analyses of ceria nanoparticles.

Notes: Contrast is made between the silver-doped and undoped CeONP samples in (A) X-ray diffraction patterns, (B) Raman spectra, and (C) DLS results. PDF 65-5923 is the standard diffraction pattern for undoped ceria of fluorite structure.

Abbreviations: CeONP, cerium oxide nanoparticles; DLS, dynamic light scattering. 
Table I Lattice parameters of and crystallite sizes of CeONP

\begin{tabular}{lll}
\hline $\mathrm{CeO}_{2}$ samples & Lattice parameter $(\mathbf{n m})$ & Crystal size $(\mathbf{n m})$ \\
\hline Undoped & 0.5412 & 8.9 \\
$\mathrm{Al}^{3+}$-doped & 0.5413 & 7.9 \\
$\mathrm{Cr}^{3+}$-doped & 0.5412 & 8.6 \\
$\mathrm{Cu}^{2+}$-doped & 0.5416 & 8.6 \\
$\mathrm{Ag}^{+}$-doped & 0.5420 & 8.1 \\
\hline
\end{tabular}

Notes: The lattice parameter was fitted to a cubic cell, based on the line positions of ten X-ray diffraction peaks. The crystallite size is calculated with the Scherrer formula using FWHM of the (III) diffraction line.

Abbreviations: $\mathrm{CeONP}$, cerium oxide nanoparticles; $\mathrm{CeO}_{2}$, cerium oxide; $\mathrm{FWHM}$, full width at half maximum.

the lattice parameters of $\mathrm{Al}^{3+}$-doped, $\mathrm{Cr}^{3+}$-doped samples are nearly identical to that of undoped $\mathrm{CeONP}$, while that of $\mathrm{Ag}^{+}$doped sample differs considerably, $0.5420 \mathrm{~nm}$. Although the previous structure study has revealed that the lattice parameter of cerium oxide nanocrystals increases considerably when the crystallite size is $<20 \mathrm{~nm},{ }^{32}$ the crystallite size is not the factor for lattice parameter difference because the crystallite size values (Table 1) fall in a very narrow range, 7.9 and 8.6 $\mathrm{nm}$. It is more reasonable to infer that the aliovalent $\mathrm{Ag}^{+}$doping creates more oxygen vacancies than other cation dopants, resulting in the lattice parameter difference.

Comparison of the Raman features of undoped and silverdoped CeONP confirms that silver doping brings forth more oxygen vacancies. The two spectra of Figure 1B show both samples are featured with a predominant peak at $457 \mathrm{~cm}^{-1}$, which results from downshifting the only allowed first-order $\mathrm{F}_{2 \mathrm{~g}}$ mode of the bulk crystal at $465 \mathrm{~cm}^{-1} \cdot{ }^{33}$ Shifting in line position, along with noteworthy asymmetry and line broadening, is common to both doped and silver-doped CeONP.
These traits have been attributed to the small crystallite size. ${ }^{32}$ The protruded feature at $540 \mathrm{~cm}^{-1}$ is unique to the sample of silver-doped CeONP, not observed in the undoped CeONP and three other doped samples. The broad band at $540 \mathrm{~cm}^{-1}$ has been identified as the contribution of oxygen vacancies, ${ }^{34}$ which strengthens the conjecture that acceptor doping of silver produces more oxygen vacancies than other dopants.

Figure 1C shows the agglomerate size distributions of undoped CeONP and Ag-doped CeONP suspensions measured with dynamic light scattering. Both measurements were taken $\sim 10$ minutes after ultrasonic treatment of two CeONP solutions of $1 \mathrm{mg} / \mathrm{mL}$ solid loading. Since no deflocculation agent is added, the average agglomerate size is $686 \mathrm{~nm}$ for undoped CeONP, $406 \mathrm{~nm}$ for Ag-doped CeONP, considerably larger than their crystallite sizes. The dispersity of two suspensions is denoted by their polydispersity index values. The polydispersity index value is 0.24 for undoped CeONP and 0.57 for Ag-doped CeONP. Both powders are rated moderately polydisperse since a monodisperse distribution requires a polydispersity index $<0.2$.

\section{Antimicrobial activity of doped and undoped ceria nanoparticles}

Through measuring broth turbidity, the growth curves of E. coli and $S$. aureus display intricate differences among the doped and undoped ceria samples, as illustrated in Figure 2A and $\mathrm{B}$, respectively. The growth data were recorded in the medium inoculated with $5 \times 10^{5} \mathrm{CFU} / \mathrm{mL}$ of bacteria in the absence and presence of $1 \mathrm{mg} / \mathrm{mL}$ CeONP sample. Because OD of 0.06 at $600 \mathrm{~nm}$ corresponds to a concentration of
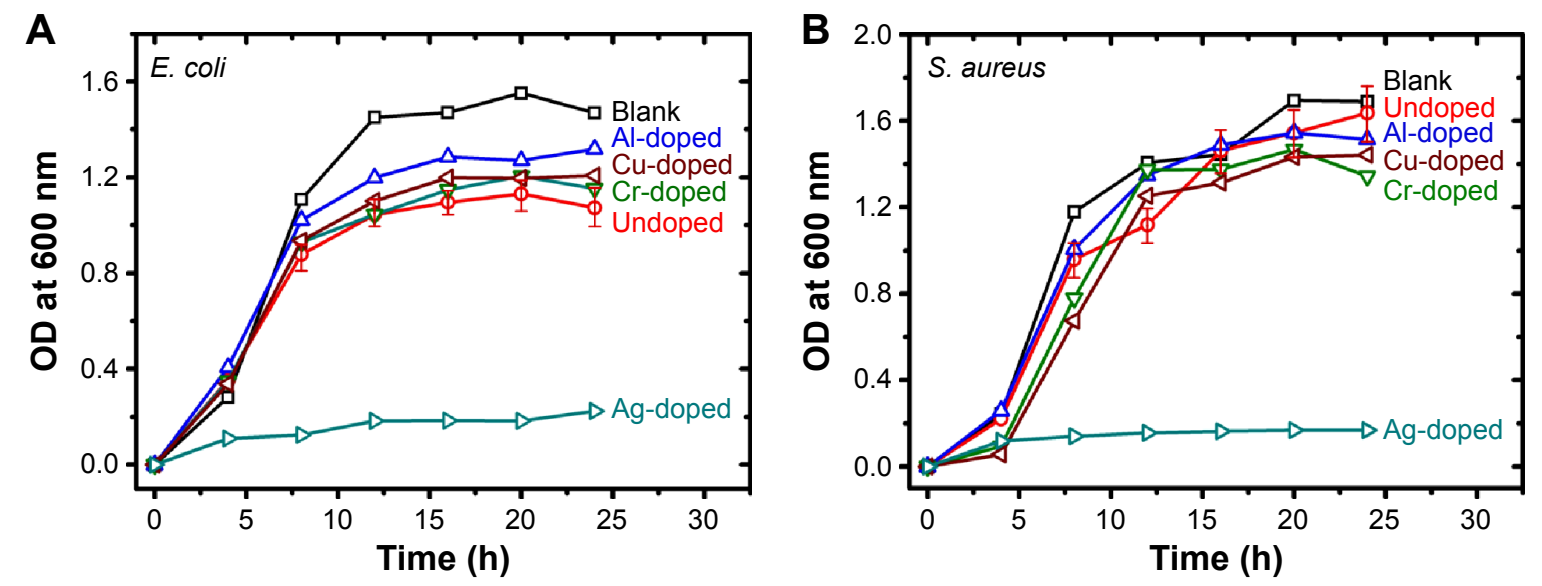

Figure 2 Growth curves measured in broth turbidity expressed as OD.

Notes: In comparison with the growth curve of a blank sample without CeONP, five growth curves are plotted for those broths containing I mg/mL CeONP and inoculated with $5 \times 10^{5} \mathrm{CFU} / \mathrm{mL}$ (A) Escherichia coli and (B) Staphylococcus aureus.

Abbreviations: CeONP, cerium oxide nanoparticles; CFU, colony-forming units; h, hours; OD, optical density. 
$10^{8} \mathrm{CFU} / \mathrm{mL}$, the error bars are smaller than the symbol sizes when values of $\mathrm{OD}$ are $<0.2$. In addition, most of the growth curve measurements are within $10 \%$ of error; the error bars are omitted for simplicity, except for the undoped CeONP data.

As can be seen in Figure 2, introducing the $1 \mathrm{mg} / \mathrm{mL}$ undoped $\mathrm{CeONP}$ caused moderate reductions in bacterial density, namely, $\sim 37 \%$ (E. coli) and $\sim 3 \%$ (S. aureus), as compared to the blank control group; however, introducing the $1 \mathrm{mg} / \mathrm{mL}$ silver-doped CeONP caused severe reductions in bacterial density, namely, $\sim 85 \%$ (E. coli) and $\sim 90 \%$ (S. aureus), as compared to the blank control group. Figure 2 also points out the unique inhibition effect of silver-doped ceria, much higher than those of the other four samples, including the undoped, $\mathrm{Al}-, \mathrm{Cu}-$, and $\mathrm{Cr}$-doped nanoparticles. Growth with Ag-doped CeONP is so constrained that it cannot reach its logarithmic phase period in 24 hours. On the other hand, the rest of broths attain their steady turbidities, signifying the stationary phase growths, after $\sim 12$ hours. However, further analysis is difficult with the turbidity data, given the high degree of entanglement involved in these four curves, especially in the growth of $S$. aureus.

The growth curve entanglement is associated with ceria interference on the turbidity reading. Even though most of ceria particles descended to the bottom before taking measurements, there was a small amount of CeONP ultrafine particles suspended and gave rise to extra optical signal, other than the signal of bacteria. When the CeONP dose is fixed, the interference may be regarded as a common background. However, as the CeONP dose varies, the interference is difficult to estimate quantitatively. Figure 3 provides a visible example. Figure $3 \mathrm{~A}$ presents the test-tube images of the E. coli broths dosed with increasing amount of silver-doped CeONP, from left to right; while Figure 3B shows those of the $S$. aureus broths. Strangely, a high content of Ag-doped CeONP does not yield a more transparent broth with a lower OD reading. Instead, the tube of $0.375 \mathrm{mg} / \mathrm{mL}$, located in the middle (tube $\mathrm{V}$ of Figure $3 \mathrm{~A}$ ), is the most transparent froth for E. coli, and the tube of $1.0 \mathrm{mg} / \mathrm{mL}$ (tube IV of Figure 3B) is the most see-through broth for $S$. aureus. The higher turbidities at high doses are caused by suspended ceria, not bacteria. Still, the preceding turbidity measurement ensures the superiority of Ag-doped CeONP, being the most disinfecting composition, but it fails to resolve finer details of the rest less effective compositions due to ceria interference.

Since the Al-, Cu-, and Cr-doped samples display disinfection effects similar to undoped CeONP, our attention henceforth focuses on comparison of the undoped and
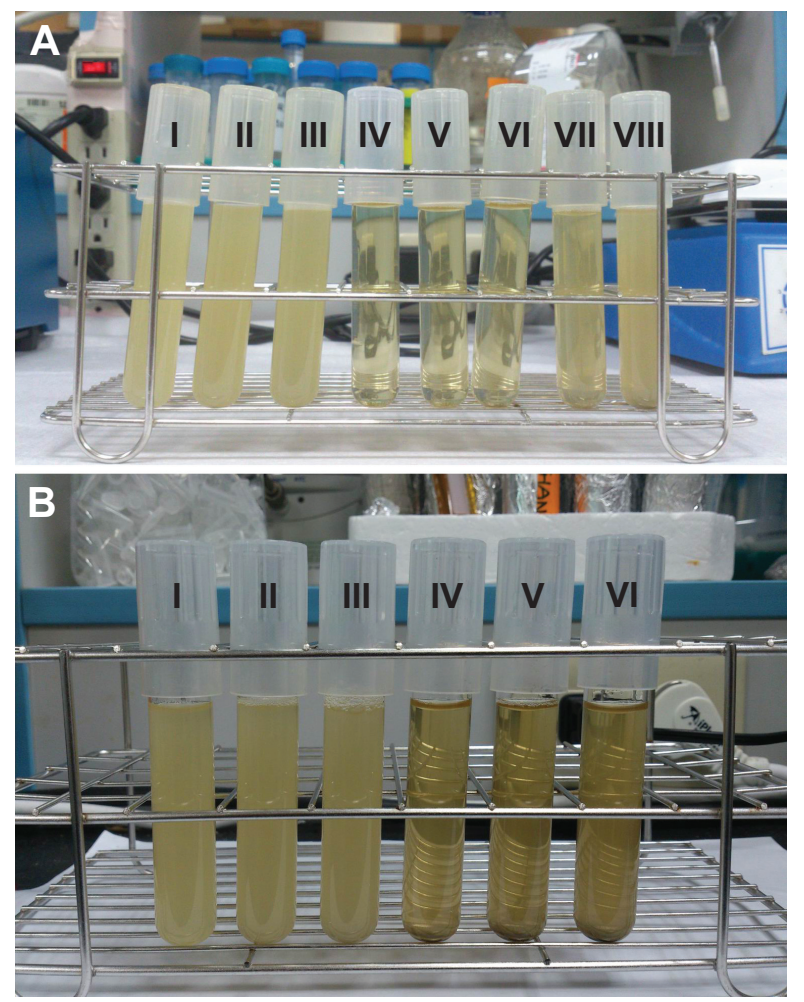

Figure 3 Interference of suspended ceria nanoparticles on turbidity. Notes: The images of the Escherichia coli broths dosed with (I) 0.0 , (II) 0.0625 (III) 0.I25, (IV) 0.25, (V) 0.375, (VI) 0.50, (VII) 1.0, and (VIII) $2.0 \mathrm{mg} / \mathrm{mL}$ Ag-doped CeONP are shown in $\mathbf{A}$ while those of the Staphylococcus aureus broths dosed with (I) 0.0, (II) 0.25, (III) 0.5, (IV) I.0, (V) I.5, and (VI) $2.0 \mathrm{mg} / \mathrm{mL}$ Ag-doped CeONP are shown in B.

Abbreviation: CeONP, cerium oxide nanoparticles.

Ag-doped samples. We turn to the standard plate count method and analyze the dose dependences of these two compositions. The plate count method examines the survival curves after 24 hours incubation, treated with ceria nanoparticles of six or seven different doses. Figure $4 \mathrm{~A}$ indicates a rather large dosage is necessary for undoped CeONP to effectively suppress the bacterial growth, especially for $E$. coli. Dosing undoped CeONP, $60 \mathrm{mg} / \mathrm{mL}$, decreases the $E$. coli counts by three orders of magnitude, and the $S$. aureus counts by six orders of magnitude in $\mathrm{CFU} / \mathrm{mL}$. Disinfection of undoped CeONP is more effective on $S$. aureus than E. coli.

In contrast, silver-doped CeONP is much more effective on both types of bacteria, compared with the undoped sample. Survival curves of Figure 4B show there is no bacteria survived when the dose is higher than $0.375 \mathrm{mg} / \mathrm{mL}$ for E. coli and $1.50 \mathrm{mg} / \mathrm{mL}$ for $S$. aureus. Hence, we locate the value of the minimal inhibitory concentrations required to inhibit the growth of $50 \%$ of bacteria (MIC50), $0.25 \mathrm{mg} / \mathrm{mL}$ for $E$. coli, and $1.0 \mathrm{mg} / \mathrm{mL}$ for $S$. aureus. Inhibitory effect 


\section{A}

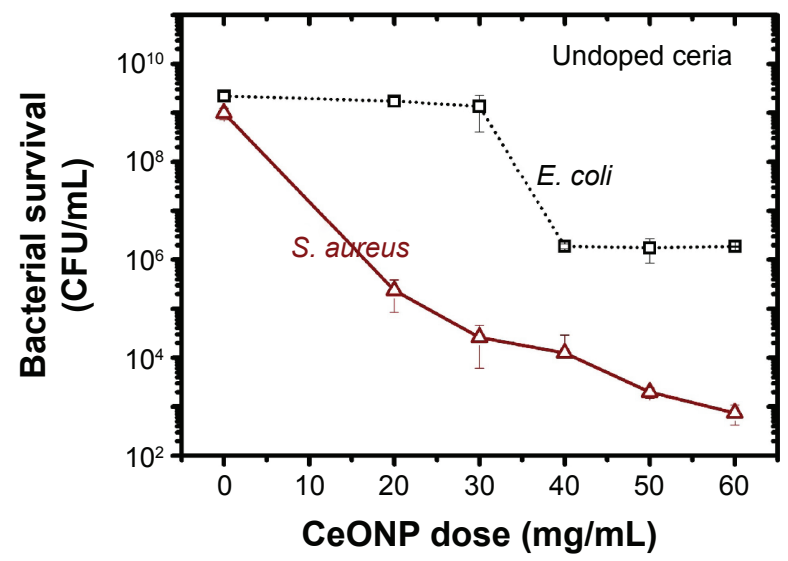

B

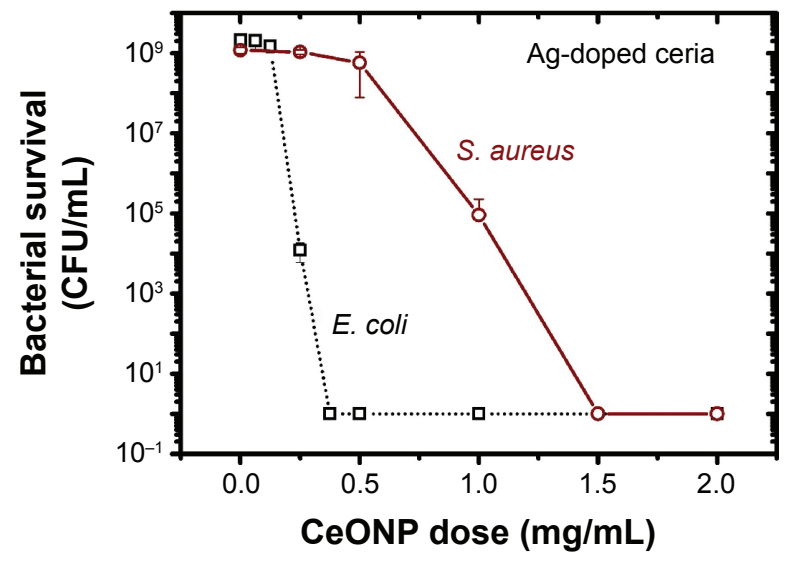

Figure 4 Bacterial survival results of the plate count method.

Notes: Doses of (A) undoped CeONP and (B) silver-doped CeONP influence the Escherichia coli and Staphylococcus aureus survivals differently after 24 hours. Bacterial inoculation is $5 \times 10^{5} \mathrm{CFU} / \mathrm{mL}$ for all samples.

Abbreviations: CeONP, cerium oxide nanoparticles; CFU, colony-forming units.

of silver-doped CeONP is more evident on Gram-negative E. coli than Gram-positive S. aureus, implying $S$. aureus possesses a potent defense system toward silver.

\section{Visualization of killing or delaying bacterial cells of Ag-doped CeONP}

Figure $5 \mathrm{~A}$ and $\mathrm{B}$ present the bright-field images of $E$. coli (initial concentration of $5 \times 10^{5} \mathrm{CFU} / \mathrm{mL}$ ) in the absence and presence of $2 \mathrm{mg} / \mathrm{mL}$ of silver-doped CeONP after 24 hours.
Without CeONP, the microfluidic flow cell is teeming with rod-shaped bacteria (Figure 5A). While with silver-doped CeONP, the microfluidic flow cell is empty, the rod-shaped cells are killed completely. Similar contrasts can be also found in the microfluidic flow cell of $S$. aureus. In the absence of silver-doped CeONP, S. aureus colonies are arranged in grape-like clusters, as shown in Figure 5C. With $2 \mathrm{mg} / \mathrm{mL}$ Ag-doped CeONP, grape-like clusters are wiped out (Figure 5D). Thus, direct visualization reveals that, at a dose
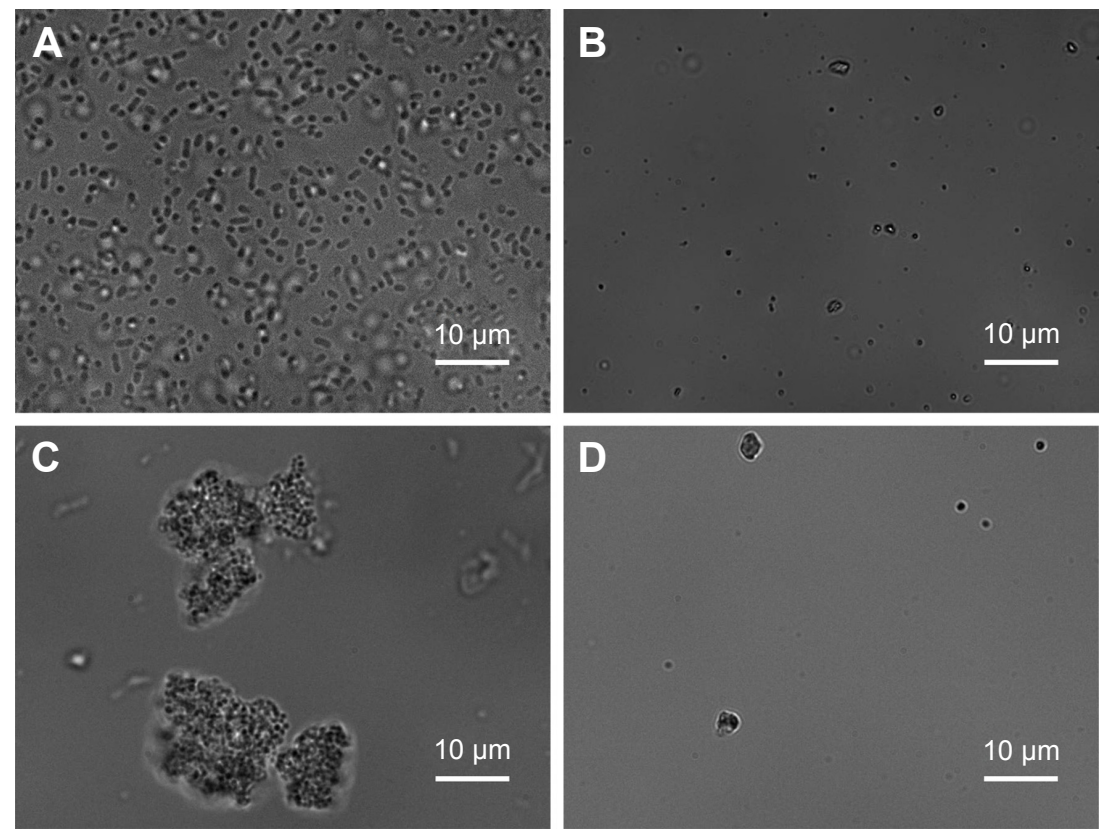

Figure 5 Images of bacteria with and without a large dose of Ag-doped CeONP.

Notes: Contrast is made on Escherichia coli growth $(\mathbf{A})$ with and (B) without the influences of $2 \mathrm{mg} / \mathrm{mL}$ of silver-doped CeONP. A similar comparison is done on Staphylococcus aureus growth (C) with and (D) without $2 \mathrm{mg} / \mathrm{mL}$ of silver-doped CeONP.

Abbreviation: CeONP, cerium oxide nanoparticles. 

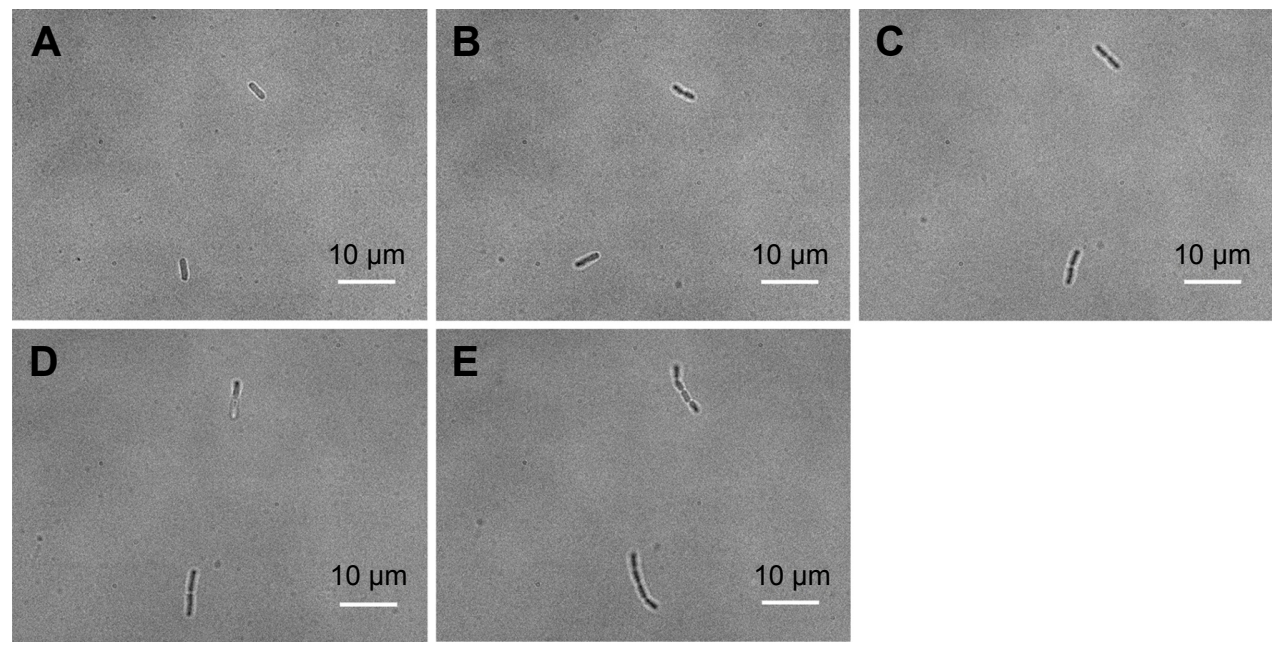

Figure $6 \mathrm{BF}$ images of Escherichia coli growth in the blank control group.

Notes: Growth without CeONP, the incubation time increases every 30 minutes; (A) 0, (B) 30, (C) 60, (D) 90, and (E) I20 minutes. Two cell divisions occur in 2 hours. Abbreviations: BF, bright-field; CeONP, cerium oxide nanoparticles.

level higher than its MIC50, Ag-doped CeONP interrupts the growth of the bacteria cells, consistent with the results of the standard plate count method.

To visualize more details of the Ag-doped CeONP influences under the microscope, we keep the dose level at MIC50 such that the bacterial cells are sufficiently affected but not being killed entirely. To conduct the real-time monitoring, bright-field images of bacteria were captured every 30 minutes for 120 minutes, while their intracellular ROS was quantified by the fluorescent probe DCFH-DA, and detected using an inverted fluorescence microscope equipped with an EMCCD camera. Figure 6A-E shows the time-dependent changes in $E$. coli population of the blank control group (initial concentration of $5 \times 10^{5} \mathrm{CFU} / \mathrm{mL}$, without Ag-doped CeONP). As can be seen in Figure 6, there were two individual E. coli bacterial cells at room temperature (Figure 6A) in the beginning; after 2 hours, there were eight $E$. coli bacterial cells (Figure 6E). Two divisions occurred during the 2-hour period. In contrast, no division occurred when $E$. coli population was treated with $0.25 \mathrm{mg} / \mathrm{mL}$ Ag-doped CeONP, as shown in Figure 7A-E. The aforementioned contrast reveals that there is a delay in the bacterial growth of E. coli tested at the dose of MIC50 $(0.25 \mathrm{mg} / \mathrm{mL}$ Ag-doped CeONP).

We further examined the connection between the presence of Ag-doped CeONP and the intracellular ROS
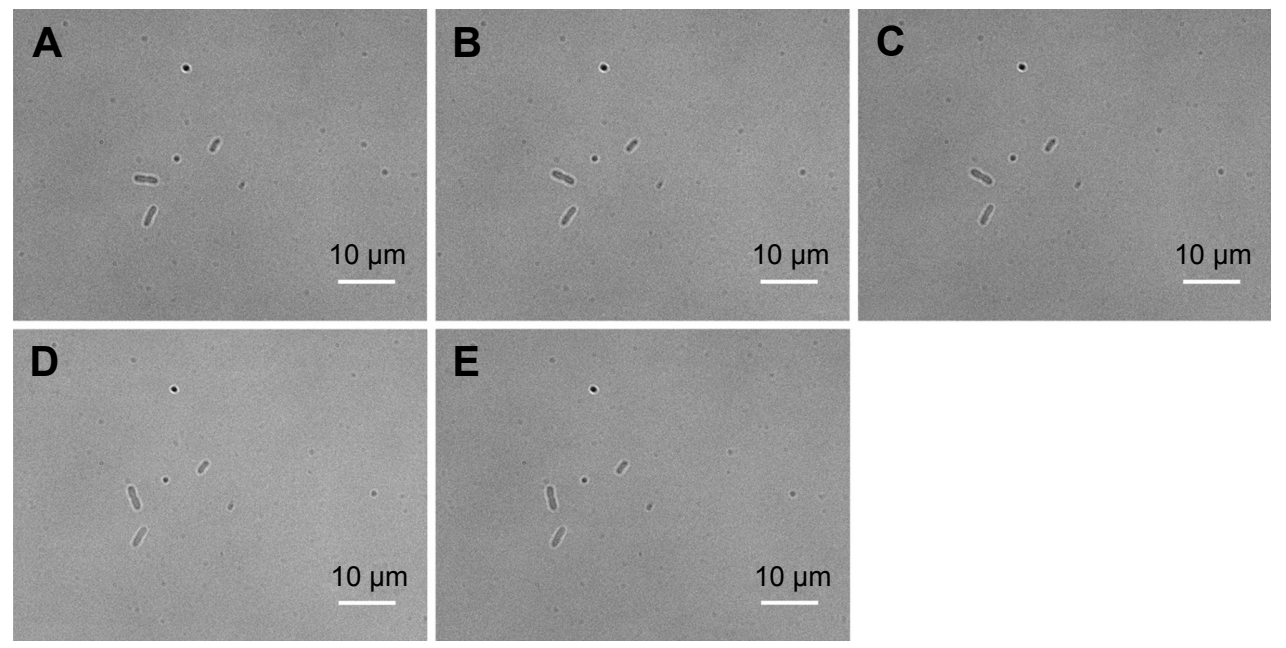

Figure $7 \mathrm{BF}$ images of Escherichia coli growth in presence of Ag-doped CeONP with MIC50 dose.

Notes: Growth with Ag-doped CeONP, the incubation time increases every 30 minutes with $0.25 \mathrm{mg} / \mathrm{mL}$; (A) 0, (B) 30, (C) 60, (D) 90 , and (E) I20 minutes. No division is observed.

Abbreviations: BF, bright-field; CeONP, cerium oxide nanoparticles; MIC50, minimal inhibitory concentrations required to inhibit the growth of $50 \%$ of bacteria. 

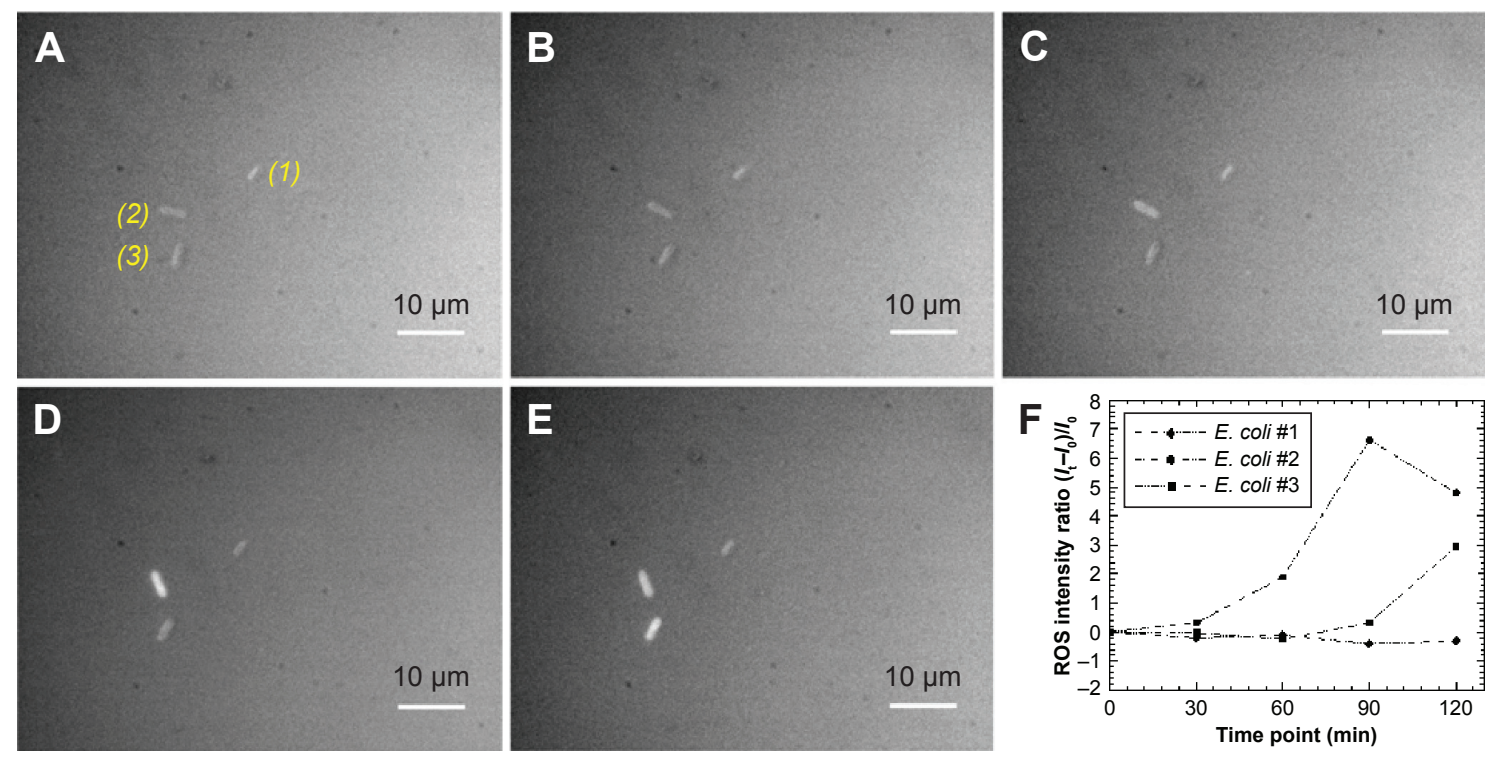

Figure 8 Fluorescence images of Escherichia coli growth in the presence of Ag-doped CeONP with MIC50 dose.

Notes: Growth with $0.25 \mathrm{mg} / \mathrm{mL}$ Ag-doped CeONP, the incubation time increases every 30 minutes; (A) 0, (B) 30, (C) 60, (D) 90, and (E) I20 minutes. (F) Timedependence of the ROS fluorescence signal within the individual living $E$. coli cell. The ROS fluorescence signifies the intracellular ROS formation.

Abbreviations: CeONP, cerium oxide nanoparticles; MIC50, minimal inhibitory concentrations required to inhibit the growth of $50 \%$ of bacteria; ROS, reactive oxygen species.

formation. Figure 8 shows the time-dependent changes of ROS fluorescence signal in three individual living E. coli cells, where the corresponding bright-field images (Figure 7) were captured at the same time intervals. We then define the ROS intensity ratio, $\left(I_{\mathrm{t}}-I_{0}\right) / I_{0}$, where $I_{0}$ and $I_{\mathrm{t}}$ represent the ROS fluorescence signal within the individual living E. coli cell at times point 0 and $t$ minutes, respectively, to examine the intracellular ROS kinetics induced by Ag-doped CeONP on E. coli cells (Figure 8F). The sequential fluorescence images indicate the intracellular ROS formation is significantly weak, namely, $\left(I_{30}-I_{0}\right) / I_{0} \approx 0$, in the first 30 minutes of incubation (Figure $8 \mathrm{~A}$ and $\mathrm{B}$ ). However, the fluorescence signals of ROS obtained from E. coli cells 2 and 3 light up after 60 minutes of incubation (Figure $8 \mathrm{C}-\mathrm{E}$ ).

For comparison purpose, the same procedure is applied to analyze $S$. aureus population and the corresponding ROS formation. Figures 9 and 10 present the time-dependent changes of $S$. aureus population (initial concentration of $5 \times 10^{5} \mathrm{CFU} / \mathrm{mL}$ ) in the absence and presence of $1.0 \mathrm{mg} / \mathrm{mL}$
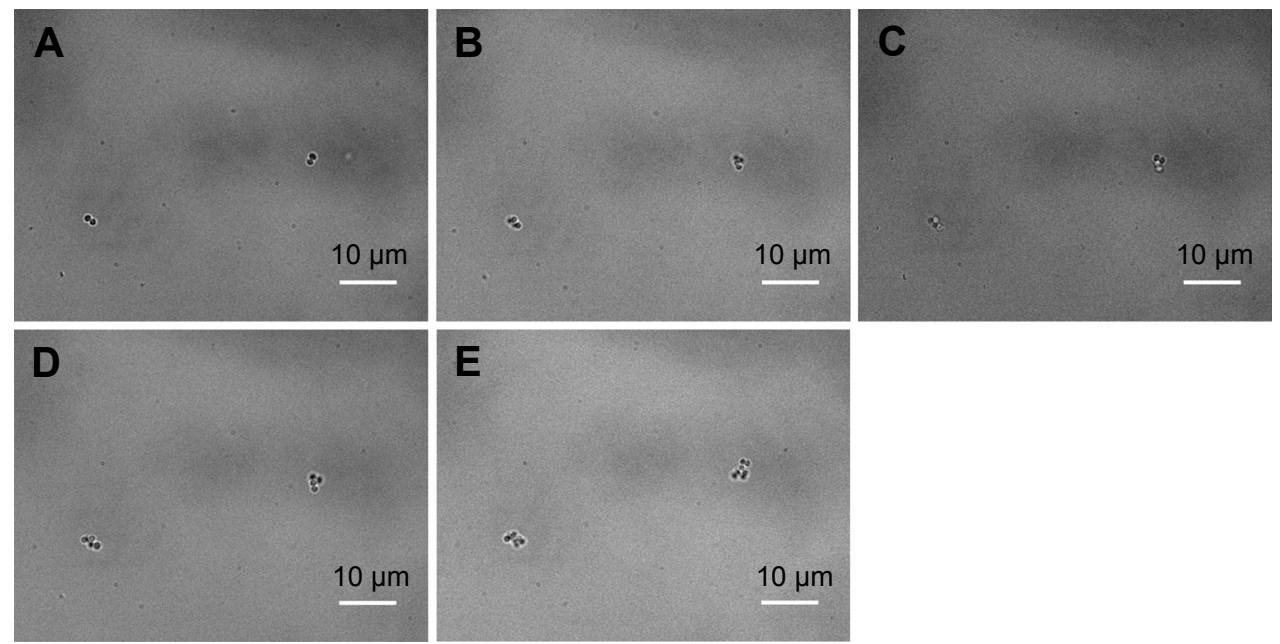

Figure $9 \mathrm{BF}$ images of Staphylococcus aureus growth in the blank control group.

Notes: Growth without CeONP, the incubation time increases every 30 minutes; (A) 0, (B) 30, (C) 60, (D) 90, and (E) I20 minutes. Two cell divisions occur. Abbreviations: BF, bright-field; CeONP, cerium oxide nanoparticles. 

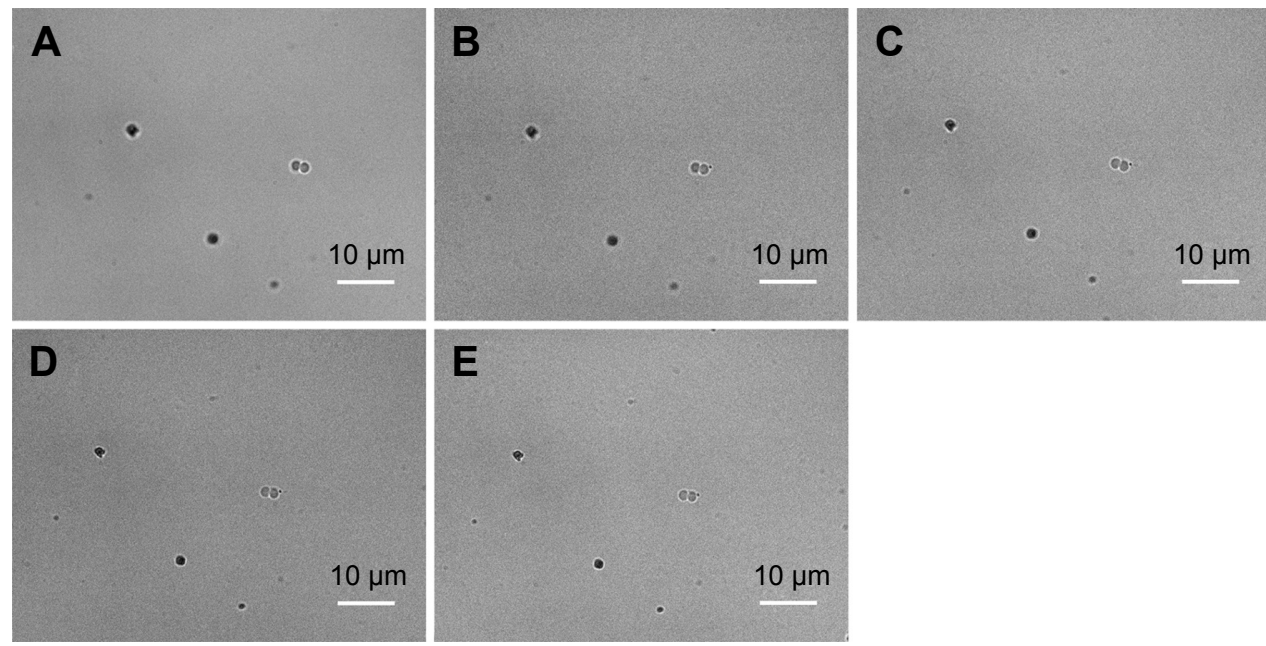

Figure 10 BF images of Staphylococcus aureus growth in the presence of Ag-doped CeONP with MIC50 dose.

Notes: Growth with $1.0 \mathrm{mg} / \mathrm{mL}$ Ag-doped CeONP, the incubation time increases every 30 minutes; (A) 0, (B) 30, (C) 60, (D) 90, and (E) I20 minutes. No cell division is seen. Abbreviations: BF, bright-field; CeONP, cerium oxide nanoparticles; MIC50, minimal inhibitory concentrations required to inhibit the growth of $50 \%$ of bacteria.

Ag-doped CeONP during the first 2 hours of incubation. Figure 9E shows a pair of S. aureus that have gone through two cell divisions, producing a pair of tetrads. It demonstrates that two divisions occur in 120 minutes. However, no division occurs when $S$. aureus was treated with $1 \mathrm{mg} / \mathrm{mL} \mathrm{Ag-doped}$ CeONP, as can be clearly seen from a series of images in Figure 10. Again, the earlier finding reveals that the bacterial growth of $S$. aureus has been obstructed in the presence of its MIC50, just like E. coli.

Similarly, the delay can be traced back to the intracellular ROS formation of $S$. aureus. Figure 11 presents the corresponding fluorescence images of Figure 10, showing intracellular ROS fluorescence signal in S. aureus. As can be seen in Figure 10, there are a pair of cells on the right, but only one of them glows in Figure 11A and B. When incubation time reaches 60 minutes, the other cell begins to give off fluorescence too, and this pair is visible in Figure 11C-E. The higher MIC50 dose for S. aureus suggests that S. aureus possesses a potent defense system. It is rational to deduce that the comparatively higher vulnerability of $E$. coli resides in the difference in cell membranes. The membrane difference makes ROS formation kinetically slower; hence, Gram-positive $S$. aureus appears more resistant to Ag-doped CeONP.
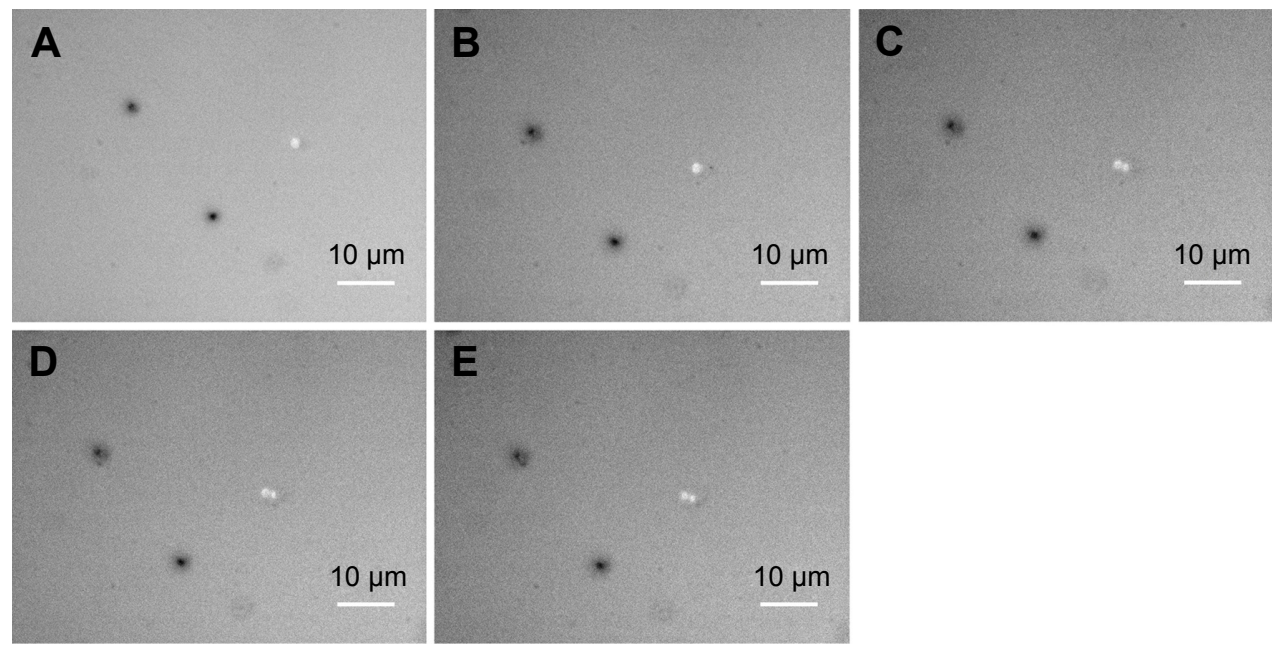

Figure II Fluorescence images of Staphylococcus aureus growth in presence of Ag-doped CeONP with MIC50 dose.

Notes: Growth with $1.0 \mathrm{mg} / \mathrm{mL}$ Ag-doped CeONP, the incubation time increases every 30 minutes (A) 0, (B) 30, (C) 60, (D) 90, and (E) I20 minutes. The ROS fluorescence signifies the intracellular ROS formation.

Abbreviations: CeONP, cerium oxide nanoparticles; MIC50, minimal inhibitory concentrations required to inhibit the growth of $50 \%$ of bacteria; ROS, reactive oxygen species. 


\section{Synergetic disinfection of silver-doped ceria}

We believe the strong disinfection effect of Ag-doped CeONP is attributed to synergetic combination of two mechanisms, namely, redox catalysis of surface oxygen vacancy and silver poisoning. The argument of silver poisoning is evidenced in Figure 12A, showing the concentrations of $\mathrm{Ag}^{+}$ ion eluted from the Ag-doped CeONP in LB medium after
24 hours. When the dose of Ag-doped CeONP is 0.375 or $1.5 \mathrm{mg} / \mathrm{mL}$, the silver ion concentration in the broth reaches 15 and 25 ppm, respectively. Furthermore, the agar diffusion method is applied to prove that the released silver is the main reason for the antibiotic rings of Figure $12 \mathrm{~B}$ and $\mathrm{C}$, where a known dose of the undoped CeONP and silver-doped CeONP is spotted on $6 \mathrm{~mm}$ diameter paper discs placed on the inoculated agar surface. Plates are incubated for 24 hours prior to
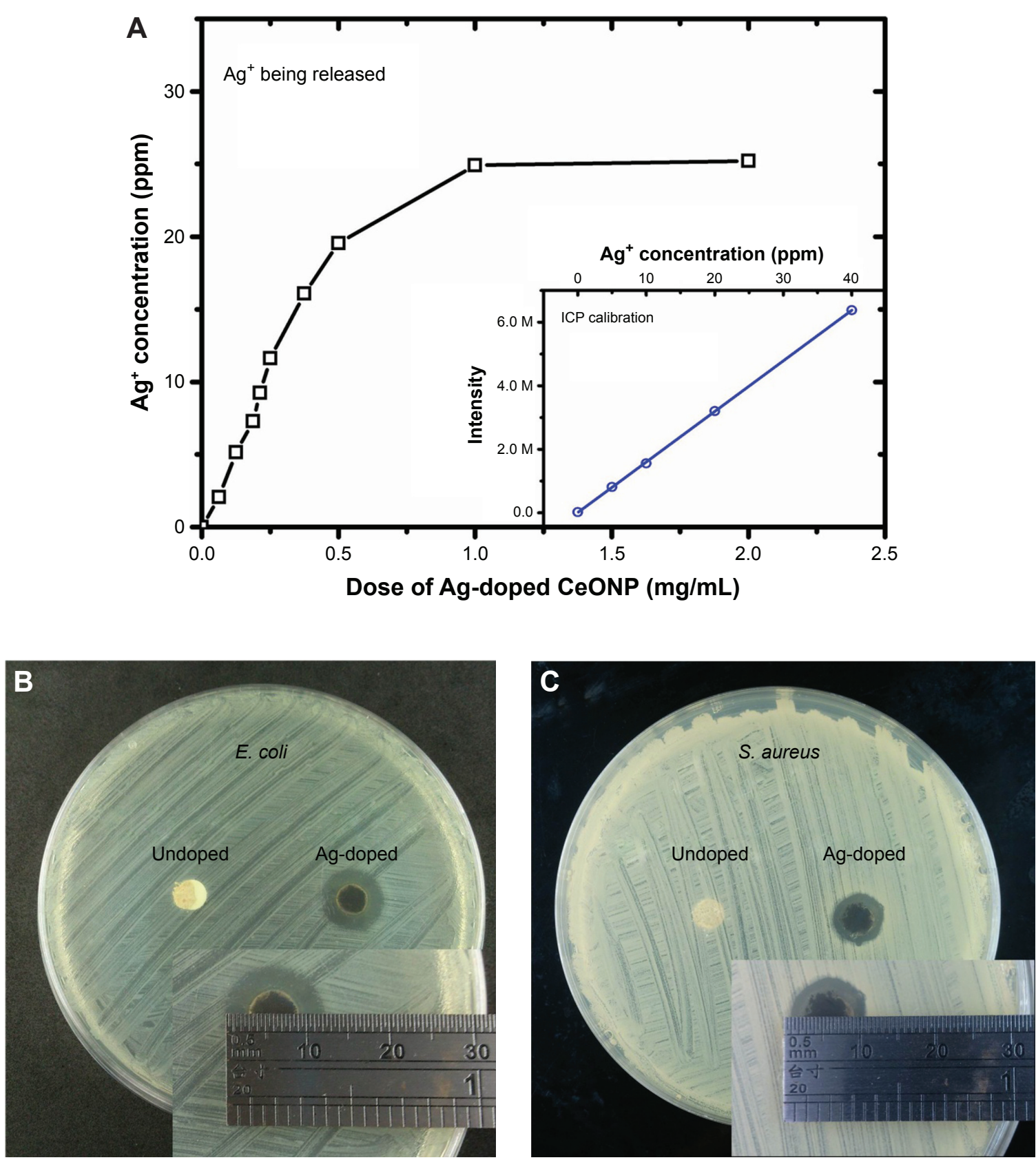

Figure 12 Silver ions eluted from Ag-doped $\mathrm{CeONP}$ and the antibiotic rings.

Notes: (A) Silver ion concentration of the broth is plotted against the dose of Ag-doped CeONP. Antibiotic rings are found around the disks of silver-doped CeONP in the (B) Escherichia coli and (C) Staphylococcus aureus plates. No ring is observed around the disks of undoped CeONP. These disks are dry powder compacts of nanoparticles, being pressed uniaxially.

Abbreviations: CeONP, cerium oxide nanoparticles; ICP, inductively coupled plasma; M, mega. 


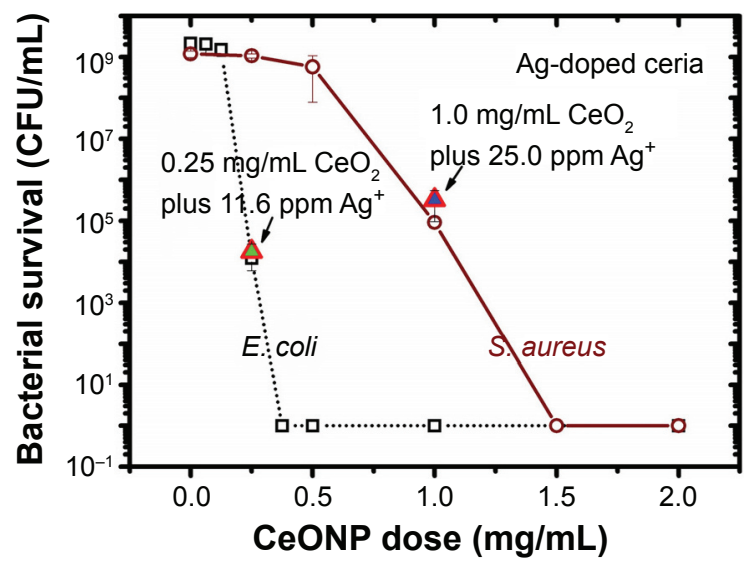

Figure I 3 Bacteria survival in an environment of a combination of undoped $\mathrm{CeONP}$ and corresponding silver concentration.

Notes: Two growth experiments are designed under an environment similar to MIC50, but with a simple combination of undoped $\mathrm{CeONP}$ and corresponding silver ion concentration.

Abbreviations: $\mathrm{CeONP}$, cerium oxide nanoparticles; CFU, colony-forming units; MIC50, minimal inhibitory concentrations required to inhibit the growth of $50 \%$ of bacteria.

determination of results. Figure 12B contrasts a $3 \mathrm{~mm}$ ring of Ag-doped CeONP and $\sim 0 \mathrm{~mm}$ ring of undoped CeONP on the $E$. coli plate. Careful inspection indicates no E. coli growth underneath the disk of undoped CeONP, suggesting disinfection of the undoped disk is short-range and relies on physical contact. Hence, the dispersion state of undoped $\mathrm{CeONP}$ is critical to the sterilization effect. On the $S$. aureus plate, Figure $12 \mathrm{C}$ shows a $2 \mathrm{~mm}$ ring of $\mathrm{Ag}$-doped CeONP and $\sim 0 \mathrm{~mm}$ ring of undoped $\mathrm{CeONP}$. The smaller ring of $\mathrm{Ag}$ doped $\mathrm{CeONP}$ reflects a relatively weak effect of $S$. aureus, consistent with Figure 4B.

Figure 13 compares the disinfection difference between $\mathrm{Ag}$-doped $\mathrm{CeONP}$ and a superposition of undoped ceria plus the released silver ions, where data points of E. coli and $S$. aureus survival are marked for these two experiments against the background of Figure 4B. The bacterial survival of a combination of undoped ceria plus the released silver ions is slightly higher than that of Ag-doped CeONP in $E$. coli and $S$. aureus broths. This finding not only justifies the synergetic effect but also supports the conjecture that $\mathrm{Ag}$ doped $\mathrm{CeONP}$ produces more oxygen vacancies such that Ag-doped CeONP disinfects better than a simple combination of ceria particles and silver ions.

\section{Conclusion}

Silver-doped CeONP has been singled out as the most disinfecting composition among the undoped and $\mathrm{Al}-, \mathrm{Cu}-$, and Cr-doped samples when the broths of E. coli and $S$. aureus are dosed with these nanoparticles and their sterilizations are evaluated with the turbidimetric and plate count methods. The disinfection effects of Ag-doped $\mathrm{CeONP}$ are also superior to a simple combination of undoped CeONP and equivalent $\mathrm{Ag}^{+}$content. This synergetic effect goes beyond the combination of ceria redox catalysis and silver poisoning. The extra benefit may be attributed to oxygen vacancy enhancement, which is manifested in the Raman analysis on the acceptor doping of silver. The disinfection effect of Ag-doped CeONP is more pronounced on E. coli than $S$. aureus, although the difference is not wide.

\section{Acknowledgments}

The authors thank Taipei Medical University (TMU) and National Taiwan University of Science and Technology (NTUST) for the financial support through project TMUNTUST-103-03. Two groups of TMU and NTUST staff contributed equally in this research work.

\section{Author contributions}

Synthesis and characterization of ceria-based nanoparticles were performed by DST and YSH. Disinfection measurements of the turbidimetric and plate count methods were carried out by TSY, PWP, KLO, and YSH. All authors contributed toward data analysis, drafting and critically revising the paper, gave final approval of the version to be published, and agree to be accountable for all aspects of the work.

\section{Disclosure}

The authors report no conflicts of interest in this work.

\section{References}

1. Bumajdadm A, Eastoe J, Mathew A. Cerium oxide nanoparticles prepared in self-assembled systems. Adv Colloid Interface Sci. 2009; 147-148:56-66.

2. Cafun JD, Kvashnina KO, Casals E, Puntes VF, Glatzel P. Absence of $\mathrm{Ce}^{3+}$ sites in chemically active colloidal ceria nanoparticles. ACS Nano. 2013;7(12):10726-10732

3. Zhang J, Nazarenko Y, Zhang L, et al. Impacts of a nanosized ceria additive on diesel engine emissions of particulate and gaseous pollutants. Environ Sci Technol. 2013;47(22):13077-13085.

4. Peng L, He X, Zhang P, et al. Comparative pulmonary toxicity of two ceria nanoparticles with the same primary size. Int J Mol Sci. 2014 15(4):6072-6085

5. Park B, Donaldson K, Duffin R, et al. Hazard and risk assessment of a nanoparticulate cerium oxide-based diesel fuel additive - a case study. Inhal Toxicol. 2008;20(6):547-566.

6. Sharpe E, Frasco T, Andreescu D, Andreescu S. Portable ceria nanoparticle-based assay for rapid detection of food antioxidants. Analyst. 2013;138(1):249-262.

7. Korsvik C, Patil S, Seal S, Self WT. Superoxide dismutase mimetic properties exhibited by vacancy engineered ceria nanoparticles. Chem Commun. 2007;10(10):1056-1058.

8. Heckert EG, Karakoti AS, Seal S, Self WT. The role of cerium redox state in the SOD mimetic activity of nanoceria. Biomaterials. 2008, 29(18):2705-2709. 
9. Karakoti A, Singh S, Dowding JM, Seal S, Self WT. Redox-active radical scavenging nano-materials. Chem Soc Rev. 2010;39(11):4422-4432.

10. Xue Y, Luan Q, Yang D, Yao X, Zhou K. Direct evidence for hydroxyl radical scavenging activity of cerium oxide nanoparticles. JPhys Chem C. 2011;115(11):4433-4438

11. Dowding JM, Dosani T, Kumar A, Seal S, Self WT. Cerium oxide nanoparticles scavenge nitric oxide radical. Chem Commun. 2012;48(40): 4896-4898.

12. Pirmohamed T, Dowding JM, Singh S, et al. Nanoceria exhibit redox state-dependent catalase mimetic activity. Chem Commun. 2010;46(16): 2736-2738.

13. Gao Y, Chen K, Ma JI, Gao F. Cerium oxide nanoparticles in cancer. OncoTargets Ther. 2014;7:835-840.

14. Pesic M, Podolski-Renic A, Stojkovic S, et al. Anti-cancer effects of cerium oxide nanoparticles and its intracellular redox activity. Chem Biol Interact. 2015;232:85-93.

15. Wason MS, Zhao J. Cerium oxide nanoparticles: potential applications for cancer and other diseases. Am J Trans Res. 2013;5(2):126-131.

16. Park EJ, Choi J, Park YK, Park K. Oxidative stress induced by cerium oxide nanoparticles in cultured BEAS-2B cells. Toxicology. 2008; 245(1-2):90-100.

17. Xia T, Kovochich M, Liong M, et al. Comparison of the mechanism of toxicity of zinc oxide and cerium oxide nanoparticles based on dissolution and oxidative stress properties. ACS Nano. 2008;2(10): 2121-2134

18. Thill A, Zeyons O, Spalla O, et al. Cytotoxicity of $\mathrm{CeO}_{2}$ nanoparticles for Escherichia coli physico-chemical insight of the cytotoxicity mechanism. Environ Sci Technol. 2006;40(19):6151-6156.

19. Hoecke K, Quik JK, Mankiewicz-Boczek J, et al. Fate and effects of $\mathrm{CeO}_{2}$ nanoparticles in aquatic ecotoxicity tests. Environ Sci Technol. 2009; 43(12):4537-4546.

20. Krishnamoorthy K, Veerapandian M, Zhang LH, Yun K, Kim SJ. Surface chemistry of cerium oxide nanocubes. J Ind Eng Chem. 2014; 20(5):3513-3517.

21. Pelletier DA, Suresh AK, Holton GA, et al. Effects of engineered cerium oxide nanoparticles on bacterial growth and viability. Appl Environ Microbiol. 2010;76(24):7981-7989.

22. Bandyopadhyay S, Peralta-Videa JR, Plascencia-Villa G, JoseYacaman M, Gardea-Torresdey JL. Comparative toxicity assessment of $\mathrm{CeO}_{2}$ and $\mathrm{ZnO}$ nanoparticles towards Sinorhizobium meliloti. J Hazard Mater. 2012;199-200:64-72.
23. Negahdary M, Mohseni G, Fazilati M, et al. The antibacterial effect of cerium oxide nanoparticles on Staphylococcus aureus bacteria. Ann Biol Res. 2012;3(7):3671-3678.

24. Yazici H, Alpaslan E, Webster TJ. The role of dextran coatings on the cytotoxicity properties of ceria nanoparticles toward bone cancer cells. JOM. 2015;67(4):804-810.

25. Alpaslan E, Yazici H, Golshan NH, Ziemer KS, Webster TJ. pHdependent activity of dextran-coated cerium oxide nanoparticles on prohibiting osteosarcoma cell proliferation. ACS Biomater Sci Eng. 2015; 1(11):1096-1103.

26. Asati A, Santra S, Kaittanis C, Perez JM. Surface-charge-dependent cell localization and cytotoxicity of cerium oxide nanoparticles. ACS Nano. 2010;4(9):5231-5331.

27. Wang Q, Perez JM, Webster TJ. Inhibited growth of Pseudomonas aeruginosa by dextran- and polyacrylic acid-coated ceria nanoparticles. Int J Nanomed. 2013;8:3395-3399.

28. Kim SH, Lee HS, Ryu DS, Choi SJ, Lee DS. Antibacterial activity of silver-nanoparticles against Staphylococcus aureus and Escherichia coli. Korean J Microbiol Biotechnol. 2011;39(1):77-85.

29. Morones JR, Elechiguerra JL, Camacho A, et al. The bactericidal effect of silver nanoparticles. Nanotechnology. 2005;16(10):2346-2353.

30. Morris VN, Farrell RA, Sexton AM, Morris MA. Lattice constant dependence on particle size for ceria prepared from a citrate sol-gel. J Phys Conference Series. 2006;26:119-122.

31. Pramanick A, Omar S, Nino JC, Jones JL. Lattice parameter determination using a curved position-sensitive detector in reflection geometry and application to $\mathrm{Sm}_{\mathrm{x} / 2} \mathrm{Nd}_{\mathrm{x} / 2} \mathrm{Ce}_{1-\mathrm{x}} \mathrm{O}_{2-\mathrm{d}}$ ceramics. J Appl Crystallogr. 2009; 42(3):490-495.

32. Zhang F, Chan SW, Spanier JE, et al. Cerium oxide nanoparticles: sizeselective formation and structure analysis. Appl Phys Lett. 2002;80(1): $127-129$.

33. McBride JR, Hass KC, Poindexter BD, Weber WH. Raman and x-ray studies of $\mathrm{Ce}_{1-\mathrm{x}} \mathrm{RE}_{\mathrm{x}} \mathrm{O}_{2-\mathrm{y}}$, where $\mathrm{RE}=\mathrm{La}, \mathrm{Pr}, \mathrm{Nd}, \mathrm{Eu}, \mathrm{Gd}, \mathrm{Tb}$. J Appl Phys. 1994;76(4):2435-2441.

34. Taniguchi T, Watanabe T, Sugiyama N, et al. Identifying defects in ceria-based nanocrystals by UV resonance Raman spectroscopy. J Phys Chem C. 2009;113(46):19789-19793.
International Journal of Nanomedicine

\section{Publish your work in this journal}

The International Journal of Nanomedicine is an international, peerreviewed journal focusing on the application of nanotechnology in diagnostics, therapeutics, and drug delivery systems throughout the biomedical field. This journal is indexed on PubMed Central, MedLine, CAS, SciSearch ${ }^{\circledR}$, Current Contents ${ }^{\circledR} /$ Clinical Medicine,

\section{Dovepress}

Journal Citation Reports/Science Edition, EMBase, Scopus and the Elsevier Bibliographic databases. The manuscript management system is completely online and includes a very quick and fair peer-review system, which is all easy to use. Visit http://www.dovepress.com/ testimonials.php to read real quotes from published authors. 